DOI: https://doi.org/10.11144/Javeriana.upsy17-3.pdpt

\title{
Psychological Distress Predicts HbA1c Trajectories among Type 1 Diabetic Adolescents*
}

\section{El estrés psicológico predice las trayectorias de $\mathrm{HbA} 1 \mathrm{c}$ en adolescentes diabéticos tipo 1}

\author{
Manuel S. Ortiz \\ Universidad de La Frontera, Chile \\ ORCID: http://orcid.org/0000-0002-7749-0699 \\ Joshua F. WILLeY \\ Monash University, Australia \\ ORCID: http://orcid.org/0000-0002-0271-6702
}

$\begin{array}{ll}\text { a Corresponding } & \text { author. }\end{array}$

How to cite: Ortiz, M. S. \& Willey, J. F. (2018). Psychological Distress Distress Predicts HbAlc trajectories Trajectories among Type 1 Diabetic Adolescents. Universitas Psychologica, 17(3), 1-8. doi: https://doi.org/10.11144/Javeriana.upsy17-3.pdpt

\begin{abstract}
Diabetic adolescents have poor metabolic control. We aimed to characterize the longitudinal association between the stress-related domains of emotional burden (EB), physician related-distress (PD), regimen-related distress $(\mathrm{RD})$, diabetes-related interpersonal distress (ID), and hemoglobin glycosylated $\left(\mathrm{HbA}_{1 \mathrm{c}}\right)$ trajectories among Type 1 diabetics Chilean adolescents. Thirty-two Type 1 diabetic adolescents $\left(\mathrm{M}_{\text {age }}=15.97 ; \mathrm{SD}=3.45\right)$ were followed for one year. $\mathrm{HbA}_{1 \mathrm{c}}$ was assessed at three time points, and a stress measure was obtained. Using a longitudinal growth curve modeling, a marginal overall negative linear trend was found in $\mathrm{HbA}_{1 \mathrm{c}}(\mathrm{b}=-0.23, \mathrm{p}=0.096)$. There was an interaction between time and PD $(b=-0.33, p<0.05)$, and a main effect of EB, RD, and ID on $\mathrm{HbA}_{1 \mathrm{c}}$. Psychological stress domains predict metabolic control trajectories. Monitoring diabetes specific stress may be a useful tool to identify adolescents at risk for poor control, and interventions that reduce such stress might lead to better management of diabetes in adolescents.

Keywords

Adolescent Diabetes; Psychological Stress; Metabolic Control.
\end{abstract}

\section{RESUMEN}

Los adolescentes diabéticos tienen un pobre control metabólico. El propósito de este estudio fue caracterizar la asociación longitudinal entre el estrés emocional (EB), estrés con el médico (PD), estrés con el tratamiento (RD) y estrés interpersonal (ID), con trayectorias de hemoglobinas glicosiladas $\left(\mathrm{HbA}_{1 \mathrm{c}}\right)$ en adolescentes diabéticos tipo 1 (DM1). Treinta y dos adolescentes DM1 $\left(\mathrm{M}_{\text {edad }}=15.97, \mathrm{DE}=3.45\right)$ fueron seguidos un año. Se obtuvo la $\mathrm{HbA}_{1 \mathrm{c}}$ tres veces en el año, más un auto-reporte de estrés. Análisis de curvas de crecimiento predijeron una tendencia lineal negativa en la trayectoria de $\operatorname{HbA} 1 \mathrm{c}(\mathrm{b}=-0.23, \mathrm{p}=$ 0.096). Hubo una interacción entre el tiempo y $\mathrm{PD}(\mathrm{b}=-0.33, \mathrm{p} \leq$ 0.05) y los efectos principales de EB, RD, e ID en $\mathrm{HbA}_{1 \mathrm{c}}$. Se concluye que el estrés psicológico predice trayectorias de $\mathrm{HbA}_{1 \mathrm{c}}$. Monitorear dominios específicos de estrés podría ser útil para identificar adolescentes con riesgo 
de tener pobre $\mathrm{HbA}_{1 \mathrm{c}}$, e intervenciones que reduzcan el estrés podrían ayudar a manejar la diabetes en adolescentes.

Palabras clave

Diabetes Adolescente; Estrés Psicológico; Control Metabólico.

Adolescence has been described as a complex evolutionary stage, characterized by greater biological, psychological and social changes (Helgeson, Escobar, Siminerio, \& Becker, 2010; Holmbeck, Friedman, Abad \& Jandasek, 2006), each of which may generate greater stress levels. Previous studies have reported elevated psychological stress among adolescent population (Pouweret al., 2013; Romeo, 2013). Further, the diagnosis of a chronic disease such as Type 1 diabetes during adolescence in addition to the treatment demands may lead to increased stress levels in this population. The psychological and behavioral challenges imposed by Type 1 diabetes and its treatment have been related to greater risk for depressive symptoms (Anarte et al., 2011; Baucom et al., 2015; McGrady, \& Hood, 2010), low treatment adherence (Moström, Ahlén, Imberg, Hansson, $\&$ Lind, 2017; Patton, 2011), and poor metabolic control (Ortiz \& Myers, 2014) among diabetic patients.

Several studies have reported positive associations between psychological stress and raised glucose levels (Faulenbach et al., 2012; Pyatak, Sequeira, Peters, Montoya, \& Weigensberg, 2013; Ortiz, Ortiz, Gatica, \& Gómez,, 2011), however these studies have limitations such as defining psychological stress as a general factor (one-dimensional construct), assessing chronic life stress, lifeevents, or self-reported perceived stress instead of a specific diabetes-distress related measure, and testing the cross-sectional association between psychological stress and glucose levels. The following study aimed to test the longitudinal association between diabetesdistress and metabolic control, using the Polonsky, Fisher, Earles, \& Dudl (2005) Diabetes Distress Scale (DDS), a specific measure developed for a diabetic population. In addition, the DDS allows for the identification of fourspecific domains: emotional burden, physician related-distress, regimen-related distress, and diabetes-related interpersonal distress. Diabetes related distress might emerge as a consequence of the diabetes diagnosis, being afraid of micro and macro-vascular complications, having unsupportive family/friends and health providers (Gonzalez, Fisher, \& Polonsky, 2011). High emotional burden may be expected as a consequence of living with diabetes, and high physician related-distress and high regimenrelated distress may be associated with the behavioral demands imposed by treatment. Because Type 1 diabetes treatment permeates all the adolescents' domains, including school and social relationships, it can be expected that there will be high diabetes-related interpersonal distress in adolescents living with Type 1 diabetes.

The purpose of this study was to test the longitudinal association between the stress-related domains of emotional burden, physician related-distress, regimenrelated distress, diabetes-related interpersonal distress, and hemoglobin glycosylated trajectories among a unique sample of Type 1 diabetic Chilean adolescents.

\section{Method}

\section{Participants}

Thirty-two Chilean Type 1 diabetic adolescents were recruited from the Chilean Juvenile Diabetes Foundation. Twelve participants were recruited from Santiago city and 20 from Temuco city. All the participants were in low socioeconomic status, users of the Chilean public health system, and were treated with an intensified insulin treatment.

The ethics committee of the Servicio de Salud Araucanía Sur approved this research. All participants voluntarily consented to participate in the study. All the participants and their parents/tutors signed a written informed consent. Participants were economically compensated 
with $\$ 10$ U.S. dollars (5000 Chilean pesos) at each time point examination.

\section{Instruments}

Stress was assessed using the four subscales from the Diabetes Distress Scale (Polonsky et al., 2005). All the subscales of the DDS are specific to the domain of diabetes. The subscales were emotional burden (EB; e.g., "feeling that diabetes is taking up too much of my mental and physical energy every day", Cronbach's $\alpha=0.89$ ), physician-related distress (PD; e.g., "feeling that my doctor doesn't know enough about diabetes and diabetes care", Cronbach's $\alpha=0.78$ ), regimen-related distress (RD; e.g., "not feeling confident in my day-to-day ability to manage diabetes", Cronbach's $\alpha=0.90)$, and diabetesrelated interpersonal distress (ID; e.g., "feeling that friends or family are not supportive enough of my self-care efforts (e.g., planning activities that conflict with my schedule, encouraging me to eat the 'wrong' foods)", Cronbach's $\alpha=0.79)$.

Glycosilated Hemoglobine $\left(\mathrm{HbA}_{1 \mathrm{c}}\right) \%$ was collected at three different time points, roughly three months apart, using the Siemens/ Bayer DCA $2000+$ equipment. Higher $\mathrm{HbA}_{1 \mathrm{c}}$ percentages indicate worse metabolic control. After the exam was conducted, the results were communicated immediately to each participant.

Participant age, sex, years living with diabetes, and whether or not they played sports (a proxy for physical activity) were collected via self-report.

\section{Data Analysis}

Data were analyzed using longitudinal growth curve models (Singer, \& Willett, 2003) with $\mathrm{R}$ version 3.0.2. Growth models allow for flexible handling of time and account for nonindependence from repeated measures on each participant. In addition to the usual linear regression parameters, growth models can have a random intercept, capturing the variability between participants in starting points (in our models, individual differences in baseline $\mathrm{HbA}_{1 \mathrm{c}}$ ) and random slopes, capturing the variability between participants in change over time (in our models, the trajectory of $\mathrm{HbA}_{1 \mathrm{c}}$ ). The models also allow the intercept and slope to be correlated, which indicates the degree of correlation between an individual's starting point and his/her change over time. For example, a strong negative correlation would indicate that the higher baseline levels of $\mathrm{HbA}_{1 \mathrm{c}}$ a participant had, the more they decline over time.

All models included a random intercept and time slope that were allowed to correlate. Time was coded as 0, 1, and 2. Participant age in years, sex, number of months living with diabetes, and whether or not they played any sports were included as covariates in all analyses. In addition, the focal variables, time and stress were entered into all models. We tested whether each type of stress interacted with time (time $\mathrm{x}$ stress interaction). If the interaction term was not significant, we dropped it and report estimates from the final model without the interaction. Effects were considered statistically significant at $\mathrm{p}<0.05$. Confidence intervals were calculated using 1,000 samples from a parametric bootstrap.

\section{Results}

\section{Subject Characteristics}

Participant demographics as well as descriptive statistics for study variables are reported in Table 1. The participants' mean age was 15.97 (SD $=3.45)$, and on average they were living with diabetes 53.31 months $(\mathrm{SD}=48.26)$. Fortyseven percent of the participants were female, and $78 \%$ reported playing a sport. 
Table 1

Subjects Characteristics

\begin{tabular}{lrr}
\multicolumn{1}{c}{ Variable } & $\mathrm{N}[\%]$ or $\mathrm{M}[\mathrm{SD}]$ & \multicolumn{1}{c}{ Range } \\
Sex (female/male) & $15 / 17[47 \% / 53 \%]$ & \\
Play a sport (yes/no) & $25 / 7[78 \% / 22 \%]$ & $10-21$ \\
Age (in years) & $15.97[3.45]$ & $3-168$ \\
Months living with diabetes & $53.31[48.26]$ & $1-5$ \\
EB & $2.27[1.01]$ & $1-5$ \\
PD & $1.85[0.94]$ & $1-5$ \\
RD & $2.36[1.10]$ & $1-4.67$ \\
ID & $2.20[1.07]$ & $6.7(50)-13.6(125)$ \\
$\mathrm{HbA}_{1 \mathrm{c}}$ Time $1 \%(\mathrm{mmol} / \mathrm{mol})$ & $8.89(74)[1.80(19.7)]$ & $6.3(45)-14.0(130)$ \\
$\mathrm{HbA}_{1 \mathrm{lc}}$ Time 2\% $(\mathrm{mmol} / \mathrm{mol})$ & $8.63(71)[1.49(16.3)]$ & $6.3(4)-1125$
\end{tabular}

$\mathrm{HbA}_{\mathrm{lc}}$ Time $3 \%(\mathrm{mmol} / \mathrm{mol}) \quad 8.43(69)[1.82(19.9)] \quad 6.0(42)-12.4(112)$

Note. $\mathrm{EB}=$ Diabetes Distress Scale (DDS) emotional burden, $\mathrm{PD}=\mathrm{DDS}$ physicianrelated distress, $\mathrm{RD}=\mathrm{DDS}$ regimen-related distress, $\mathrm{ID}=$ DDS interpersonal distress.

First, we examined a growth model over time and covariates but not stress to characterize the overall trajectory. For this baseline model, the estimate for the intercept was $b=8.8$, and the random effect, EC $1=1.67$, indicating that the overall mean intercept was 8.8 and the standard deviation of individual subject variability about that mean was 1.67 . The overall time effect was not statistically significant $(\mathrm{b}[95 \% \mathrm{CI}]=-0.23$ $[-0.50,0.04], p=0.096)$, although the trend was for a decrease in $\mathrm{HbA}_{1 \mathrm{c}}$ levels over the course of this study. The random effect for the time slope was EC $2=0.55$, which is large relative to the mean, suggesting that although the trend was a slight decrease, there is substantial individual variability in linear time slope. The estimated correlation between the random intercept and time slope parameters was -0.59 , indicating that subjects who were above the mean at baseline tended to have more negative time slopes. None of the covariates (age, sex, whether play sports, and months with diabetes) approached statistical significance.

Next we tested whether each of the diabetes specific stress measures predicted the trajectory of $\mathrm{HbA}_{1 \mathrm{c}}$. There was a significant interaction between time and physician-related distress (b $[95 \% \mathrm{CI}]=-0.33[-0.60,-0.06], \mathrm{p}<0.05)$ such that at baseline, participants who were significantly higher in physician-related distress had higher $\mathrm{HbA}_{1 \mathrm{c}}$ levels, but there were no significant differences for the second and third assessments (Figure 1). The time $\mathrm{x}$ stress interaction was not statistically significant for emotional burden, regimen-related distress, or interpersonal distress (Table 2).

Figure 1

Predicted $\mathrm{HbA}_{1 c} \%$ over time for high and low diabetes distress
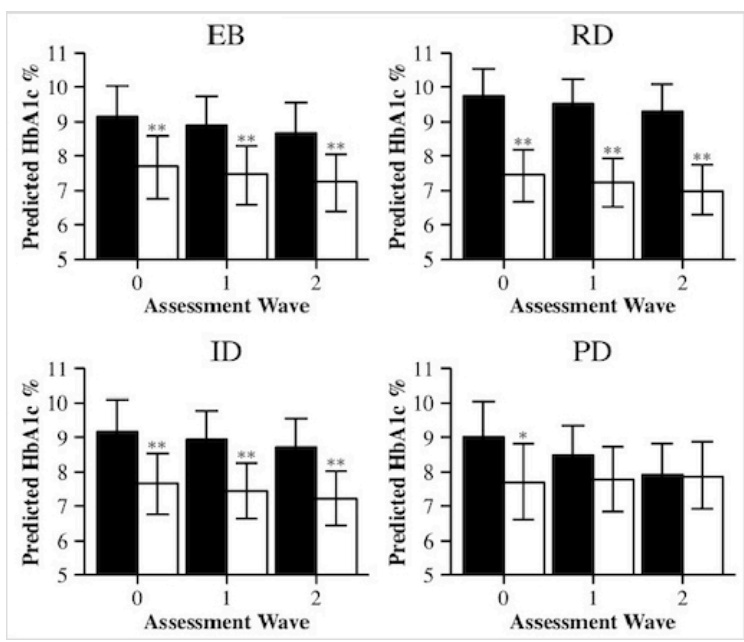

Note. $\mathrm{EB}=$ Diabetes Distress Scale (DDS) emotional burden, $\mathrm{PD}=\mathrm{DDS}$ physician-related distress, $\mathrm{RD}=\mathrm{DDS}$ regimen-related distress, $\mathrm{ID}$ $=$ DDS interpersonal distress. Black bars $=+1$ $S D$ above the mean, white bars $=-1$ SD below the mean (white bars) for each stress variable. Bars show predicted means holding covariates at the mean or mode with $95 \%$ bootstrapped confidence intervals. Asterisks indicate whether the difference between $+1 S D$ and $-1 S D$ are statistically significant. ${ }^{*} p<0.05 * * p<0.01$

Table 2

Longitudinal Growth Curve Models Predicting $\mathrm{HbA}_{1 c} \%$ from Diabetes Distress

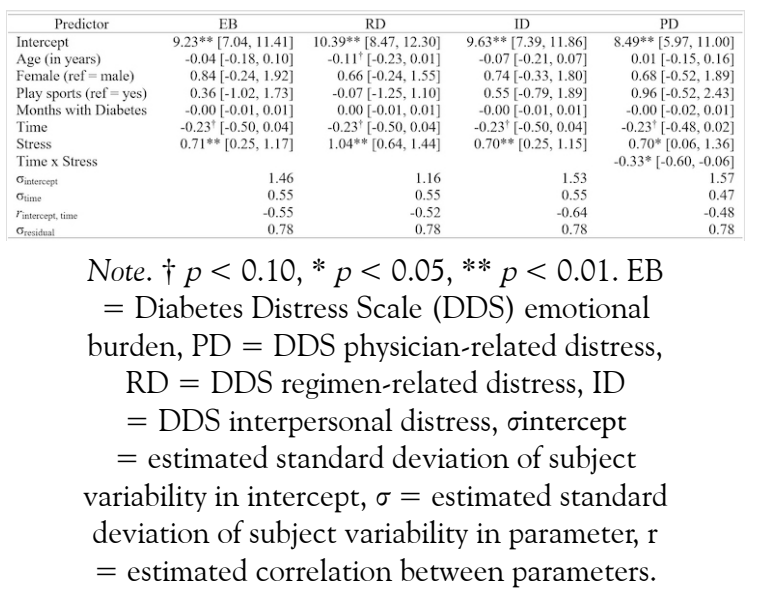

There were significant main effects of emotional burden, regimen-related distress, and 
interpersonal distress on $\mathrm{HbA}_{1 \mathrm{c}}$ levels, such that higher stress scores were significantly associated with higher $\mathrm{HbA}_{1 \mathrm{c}}$ levels across all three timepoint examinations (all ps $<0.01$, see Table 2 and Figure 1).

\section{Discussion}

Our study tested the longitudinal association between psychological stress and $\mathrm{HbA}_{1 \mathrm{c}}$ trajectories in a unique sample of Type 1 diabetic Chilean patients. To our knowledge, few studies have tested $\mathrm{HbA}_{1 \mathrm{c}}$ trajectories among Type 1 diabetic patients, using specific diabetes distressrelated domains as predictors. As previously mentioned, most studies testing the association between psychological stress and metabolic control in Type 1 diabetes have been crosssectional, or have used non-specific diabetes distress related measures such as chronic life stress or perceived stress. Our study addressed these limitations by testing the longitudinal association between specific diabetes distressrelated domains and $\mathrm{HbA}_{1 \mathrm{c}}$ trajectories. In addition, the relations were tested among a unique sample of low socioeconomic, Chilean adolescents.

As expected, the four stress domains tested were associated with $\mathrm{HbA}_{1 \mathrm{c}}$ at baseline, such that higher stress scores were significantly related to higher $\mathrm{HbA}_{1 \mathrm{c}}$ levels. Although participants who were high in emotional burden, regimenrelated distress, and interpersonal distress had worse metabolic control across all three time points, the association between physician-related distress and $\mathrm{HbA}_{1 \mathrm{c}}$ was significant at baseline only, but not at the end of the assessment.

These results are consistent with previous studies that demonstrated a longitudinal association between psychological stress and metabolic control in Type 1 diabetic patients, (Helgeson et al., 2010; Helgeson, Honcharuk, Becker, Escobar, \& Siminerio, 2011). Type 1 diabetes is a stressful chronic disease that requires adoption of new behaviors, changes in lifestyle behaviors, and a constant selfmonitoring that can result in elevated stress levels, especially in adolescents. Furthermore, it is not surprising that participants scoring high on these four specific distress domains had worse metabolic control than those reporting low diabetes-related distress. Adolescence is characterized as an evolutionary stage in which social life and food are central elements (Borus, \& Laffel, 2010). The diet restrictions, the insulin treatment, and the blood sugar self-monitoring, among other behavioral demands imposed by the diabetic treatment may overwhelm adolescents and lead to emotional burden, regimen relateddistress, and interpersonal-distress (Monaghan, Helgeson, \& Wiebe, 2015).

Similarly, patients reporting high physicianrelated distress also had worse metabolic control than those reporting low physician-distress at baseline. This result is particularly relevant in this unique sample. Given their low socioeconomic status, these participants only have access to the Chilean public health system with the restriction that they can neither choose nor change their diabetic care physician, if they are unsatisfied with their care. Previous studies have shown that the relationship between patients and health care professionals is crucial to achieving good diabetic control (Beverly, Worley, Court, Prokopakis, \& Ivanov, 2016; Bundesmann, \& Kaplowitz, 2011). If the patient negatively evaluates the relationship with health care professionals, it may affect other processes such as communication and satisfaction with caregivers, and these may interfere with treatment adherence and thus indirectly alter metabolic control (Jones et al., 2014).

Although the overall time effect was not statistically significant, a trend for a decrease in $\mathrm{HbA}_{1 \mathrm{c}}$ levels over the course of this study was found. As part of our procedure, all participants received an oral and written report with their $\mathrm{HbA}_{1 \mathrm{c}}$ levels at the end of each visit. This immediate feedback may have had a beneficial effect on the participants' metabolic control. In fact, previous studies have reported that immediate feedback has positive effects on Type 1 diabetes metabolic control (Li, Zhou, Chen, Song, \& Xue, 2012; Polonsky et al., 2011). 
This study had some limitations. Treatment adherence was not measured so it was not possible to test the association between these specific psychological distress domains, and the behaviors requested by the diabetic treatment, making it harder to estimate if the psychological stress was related to $\mathrm{HbA}_{1 \mathrm{c}}$ via a behavioral pathway or physiological dysregulation pathway. It is well known that psychological stress may exert its effect on $\mathrm{HbA}_{1 \mathrm{c}}$ directly, for instance, through the hypothalamic-pituitaryadrenal axis or sympathetic-adrenal-medullary system dysregulation (Ortiz, Willey, \& Chiang, 2014) or altering adherence to health behaviors considered pillars for diabetic treatment, such as increasing sugary food consumption and decreasing physical activity. Another limitation was the small sample size of this unique sample, which suggests caution in the interpretation of these findings. This study also has several strengths including the use of longitudinal growth curve modeling, the measure of a robust biomarker for metabolic control in Type 1 diabetic patients, the use of a well-validated measure for diabetes related distress, and the study of a unique sample of Chilean adolescents.

Future research should include a large sample size and include understudied populations such as adolescents or culturally diverse backgrounds to generalize results to the population. Our results demonstrate a relationship between psychological stress and $\mathrm{HbA}_{1 \mathrm{c}}$; interventions targeting psychological stress among Type 1 diabetic adolescents may be beneficial to demonstrate whether there is a causal association between psychological stress and $\mathrm{HbA}_{1 \mathrm{c}}$. Furthermore, a study targeting psychological stress among Type 1 diabetic adolescents that includes daily techniques will allow a better understanding of the relationship of psychological stress with $\mathrm{HbA}_{1 \mathrm{c}}$.

\section{Acknowledgements}

This research was partially supported by the Chilean National Council for Scientific Research and Technology FONDECYT (11140454, Chile) granted to Manuel S. Ortiz and the Fund for Innovation and Competitiveness (FIC) of the Chilean Ministry of Economy, Development and Tourism, through the Millennium Science Initiative, Grant $\mathrm{N}^{\circ}$ IS130005.

\section{References}

Anarte, M., Carreira, M., Ruiz de Adana, M., Caballero, F., Godoy, A., \& Soriguer, F. (2011). Precisión del diagnóstico de depresión en pacientes con diabetes mellitus tipo 1. Psichotema, 23, $606-610$.

Baucom, K. J. W., Queen, T. L., Wiebe, D. J., Turner, S. L., Wolfe, K. L., Godbey, E. I., ... Berg, C. A. (2015). Depressive Symptoms, Daily Stress, and Adherence in Late Adolescents with Type 1 Diabetes. Health Psychology: Official Journal of the Division of Health Psychology, American Psychological Association, 34(5), 522-530. h ttps://doi.org/10.1037/hea0000219

Beverly, E., Worley, M., Court, A., Prokopakis, K., \& Ivanov, N. (2016). Patientphysician communication and diabetes self-care. Journal of Clinical Outcomes Management, 23(11), 509 - 518. Retrieved from http://www.turner-white.com/pdf/jco

Borus,m_hnov \$diatteettes.p.df (2010) Adherence challenges in the management of Type 1 diabetes in adolescents: prevention and intervention. Current Opinion in Pediatrics, 22 (4), 405 - 411. https://doi.org/10.1097/M OP.0b013e32833a46a7

Bundesmann, R., \& Kaplowitz, S. (2011). Provider communication and patient participation in diabetes self-care. Patient Education Counseling, 85(2), 143 - 147. htt ps://doi.org/10.1016/j.pec.2010.09.025

Faulenbach, M., Uthoff, H., Schwegler, K., Spinas, G., Schmid, C., \& Wiesli, P. (2012). Effect of psychological stress on glucose control in patients with type 2 diabetes. Diabetic Medicine, 29(1), 128 131. https://doi.org/10.1111/j.1464-5491.2 011.03431.x. 
Gonzalez, J., Fisher, L., \& Polonsky, W. (2011). Depression in diabetes: Have we been missing something important? Diabetes Care, 34(1), 236 - 239. https://doi.org/10.2 $337 / \mathrm{dc} 10-1970$

Helgeson, V., Escobar, O., Siminerio, L., \& Becker, D. (2010). Relation of Stressful Life Events to Metabolic Control Among Adolescents With Diabetes: 5Year Longitudinal Study. Health Psychology, 29(2), 153-159. http://doi.org/10.1037/a00 18163

Holmbeck, G., Friedman, D., Abad, M., \& O., \& Siminerio, L. (2011). A focus on blood glucose monitoring: relation to glycemic control and determinants of frequency. Pediatric Diabetes, 12, 25 - 30.

Helgeson, V., Honcharuk, E., Becker, D., Escobar, Jandasek, B. (2006). Development and psychopathology in adolescence. In D. A. Wolfe \& E. J. Mash (Eds.), Behavioral and emotional disorders in adolescents: Nature, assessment, and treatment (pp. 21-55). New York: The Guilford Press.

Jones, A., Gladstone, B., Lübeck, M., Lindekilde, N., Upton, D., \& Vach, W. (2014). Motivational interventions in the management of $\mathrm{HbA1c}$ levels: a systematic review and meta-analysis. Primary Care Diabetes, 8(2), 91 - 100. https://10.1016/j.p cd.2014.01.009

Li, L., Zhou, J., Chen, H., Song, Y., \& Xue, Y. (2012). Effect of HbA1c combined FPG on screening diabetes in health check-up. Asian Pacific Journal of Tropical Medicine, 5(6), 472 - 475.

McGrady, E., \& Hood, K. (2010). Depressive symptoms in adolescents with Type 1 diabetes: Associations with longitudinal outcomes. Diabetes Research and Clinical Practice, 88(3), e35 -e37. https://doi.org/10 $.1016 /$ j.diabres.2010.03.025

Monaghan, M., Helgeson, V., \& Wiebe, D. (2015). Type 1 diabetes in young adulthood. Current Diabetes Reviews, 11 (4), 239-250. https://doi.org/10.2174/15733998 11666150421114957

Moström, P., Ahlén, E., Imberg, H., Hansson,
P., \& Lind, M. (2017). Adherence of selfmonitoring of blood glucose in persons with type 1 diabetes in Sweden. BMJ Open Diabetes Research E Care, 5(1), e000342. ht tps://doi.org/10.1136/bmjdrc-2016-000342

Ortiz, M. \& Myers, H. (2014). Control metabólico en pacientes diabéticos tipo 1chilenos: rol del estrés psicológico. Revista Médica de Chile, 142, 451 - 457.

Ortiz, M., Ortiz, E., Gatica, A., \& Gómez, D., (2011). Factores Psicosociales Asociados a la Adherencia al Tratamiento de la Diabetes Mellitus Tipo 2. Terapia Psicológica, 29(1), 5 - 11. https://doi.org/10 $.4067 / S 0718-48082011000100001$

Ortiz, M., Wiley, J., \& Chiang, J. (2014). How stress gets under the skin o como el estrés psicológico se introduce bajo la piel. Revista Médica de Chile, 142(6), 767 774. https://doi.org/10.4067/S0034-988720 14000600011

Patton, S. (2011). Adherence to Diet in Youth with Type 1 Diabetes. Journal of the American Dietetic Association, 111, 550 555.

Polonsky, W., Fisher, L., Earles, J., \& Dudl, R. (2005). Assessing psychosocial distress in diabetes: Development of the diabetes distress scale. Diabetes Care, 28(3), 626 631. https://doi.org/10.2337/diacare.28.3.6 26

Polonsky, W., Fisher, L., Schikman, C., Hinnen, D., Parkin, C., Jelsovsky ... Wagner, R. S. (2011). Structured self-monitoring of blood glucose significantly reduces A1C levels in poorly controlled, noninsulin-treated type 2 diabetes: results from the Structured Testing Program study. Diabetes Care, 34(2), 262 - 267. https://doi.org/10.2337/dc10-17 32

Pouwer, F., Wijnhoven, H. A. H., UjcicVoortman, J. K., de Wit, M., Schram, M. T., Baan, C. A., \& Snoek, F. J. (2013). Ethnic aspects of emotional distress in patients with diabetes - the Amsterdam Health Monitor Study. Diabetic Medicine, 
30(1), E25-E31. https://doi.org/10.1111/d me.12031

Pyatak, E., Sequeira, P., Peters, A., Montoya, L., \& Weigensberg, M. (2013). Disclosure of psychosocial stressors affecting diabetes care among uninsured young adults with Type 1 diabetes. Diabetic Medicine, 30(9), 1140 - 1144. https://doi.org/10.1111/dme.1 2248

Romeo, R.D. (2013). The teenage brain: The stress response and the adolescent brain. Current Direction in Psychological Science, 22(2), $140-145$.

Singer, J.D., \& Willett, J.B. (2003). Applied Longitudinal Data Analysis: Modeling Change and Event Occurrence. New York: Oxford Univ. Press.

Notes

* Research article. 